\title{
Oxidation of phosphine by sulfur or selenium involving a catalytic cycle in the interconversion of monomer and tetramer forms of copper-maleonitriledithiolate complexes
}

\author{
BIPLAB K MAITI and SABYASACHI SARKAR* \\ Department of Chemistry, Indian Institute of Technology, Kanpur 208016 \\ e-mail: abya@iitk.ac.in
}

MS received 11 August 2008; revised 6 September 2008

\begin{abstract}
The addition of triphenylphosphine $\left(\mathrm{PPh}_{3}\right)$, into $\left[\mathrm{Et}_{4} \mathrm{~N}\right]_{4}\left[\mathrm{Cu}_{4}(\mathrm{mnt})_{4}\right]$ shifted its characteristic electronic spectral band at $377 \mathrm{~nm}$ to $372 \mathrm{~nm}$ which is identical to that of the monomeric species, $\left[\mathrm{Et}_{4} \mathrm{~N}\right]\left[\mathrm{Cu}(\mathrm{mnt})\left(\mathrm{PPh}_{3}\right)\right]$. This reaction was followed by electrochemical study and also by ${ }^{31} \mathrm{P}$ NMR spectroscopy. Such interconversion with the participation of breaking of bridging copper- $\mu_{3}$-sulfur bond with the formation of new copper-phosphorous bond led to the development of a catalytic cycle using excess $\mathrm{PPh}_{3}$ and $\mathrm{S}$ or Se as the reacting substrates. The turnover number for the oxidation of $\mathrm{PPh}_{3}$ by $\mathrm{S}$ was found to be $0.8 \times 10^{-2} \mathrm{~s}^{-1}$ and that with Se was $0.6 \times 10^{-2} \mathrm{~s}^{-1}$ using this catalytic system.
\end{abstract}

Keywords. Monomer $\leftrightarrow$ tetramer interconversion; catalytic cycle; phosphine oxidation reduction; sulfur; selenium.

\section{Introduction}

Transition metal-sulfur bonds are ubiquitous not only in metalloenzymes but also present in man-made functional materials, in catalysts with various architectures for structural interest. ${ }^{1}$ The sulfur atoms present in these entities serve as terminal or bridging ligands to metal ions to construct various types of molecular structures. ${ }^{2-3}$

$\mathrm{Cu}^{\mathrm{I}}$ ion with 1,1- or 1,2-dithiolene chelating ligands is known to form multinuclear or polynuclear complexes. ${ }^{4,5}$ Sources of dithiolene sulfur ligands span like maleonitriledithiolate, (mnt), dithiosquarate (dts), benezene-1,2-dithiolate (bdt), iso-maleonitriledithiolate (i-mnt) (scheme 1). The two sulfurs present in these dithiolene ligands contribute diverse bridging mode like $\mu_{1}-\mathrm{S}$ and $\mu_{2}$-S.

$\left\{\mathrm{Cu}_{8} \mathrm{~S}_{12}\right\}$ core is a common feature in what appear to be a typical class of cluster obtained by the reaction of cuprous ions and bidentate sulfur chelating ligands. An outstanding common structural feature in $\left[\mathrm{Cu}_{8}(i-\mathrm{mnt})_{6}\right]^{4-},\left[\mathrm{Cu}_{8}(\mathrm{dts})_{12}\right]^{4-}$, and $\left[\mathrm{Cu}_{8}(\mathrm{mnt})_{6}\right]^{4-}$ clusters $^{4,5}$ is the similarity of cubic structure where all the coordinated sulfurs are attached as $\mu_{2}-\mathrm{S}$ bridging mode. Recently, we have reported the tri-

\footnotetext{
*For correspondence
}

nuclear, $\left[\mathrm{Cu}_{3}(\mathrm{mnt})_{3}\right]^{4}$ and tetranuclear, $\left[\mathrm{Cu}_{4}(\mathrm{mnt})_{4}\right]^{4-}$ complexes ${ }^{6,7}$ where the coordinated sulfurs vary their attachment in $\mu_{1}-\mathrm{S}$ and $\mu_{2}-\mathrm{S}$ bridging modes with their interconversion leading to octanuclear complex.

The cubane dithiolene cluster with iso-maleonitriledithiolate $(i$-mnt) ligand on oxidation by elemental sulfur led to sulfur rich copper-dithiolene cluster. ${ }^{4 a}$ The added sulfurs in turn may be removed from this sulfur-rich cluster by using $\mathrm{PPh}_{3}$ to yield tetranuclear cluster with $\mathrm{SPPh}_{3}$ as a by-product (scheme 2).

We were interested to explore similar chemistry using maleonitriledithiolate (mnt) ligand. The teranuclear and mononuclear $\mathrm{Cu}^{\mathrm{I}}$-mnt complexes are structurally characterized by us. ${ }^{6}$ Here, we report a clean inter conversion between tetramer and monomer complex using elemental sulfur (and also independently with selenium) and $\mathrm{PPh}_{3}$ to invoke a catalytic cycle that has been characterized by spectroscopic methods such as UV/Vis, ${ }^{31} \mathrm{P}$ NMR and by cyclic voltammetric study.

\section{Experimental}

All spectroscopic measurements were performed under argon atmosphere to prevent aerial oxidation of the complexes. Solvents used for the spectro- 
<smiles>N#CC([S-])=C([S-])[S-]</smiles>

mnt<smiles>[CH]C([SiH3])=C([S-])[S-]</smiles>

$i-\mathrm{mnt}$<smiles>[Si]c1ccccc1S</smiles>

bdt

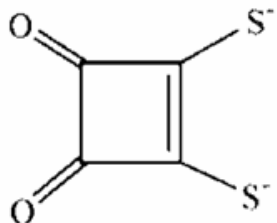

dts

Scheme 1.

$\left[\mathrm{Bu}_{4} \mathrm{~N}\right]_{4}\left(\mathrm{Cu}_{8}(i-\mathrm{mnt})_{6}\right]+\mathrm{S} \rightarrow\left[\mathrm{Bu}_{4} \mathrm{~N}\right]_{6}\left[\mathrm{Cu}_{6}(\mathrm{~S}, i-\mathrm{mnt})_{6}\right]$

$\left[\mathrm{Bu}_{4} \mathrm{~N}\right]_{6}\left(\mathrm{Cu}_{6}(S, i-\mathrm{mnt})_{6}\right]+\mathrm{PPh}_{4} \rightarrow$

$$
\left[\mathrm{Bu}_{4} \mathrm{~N}\right]_{4}\left[\mathrm{Cu}_{4}(i-\mathrm{mnt})_{4}\right]+\mathrm{SPPh}_{3}
$$

Scheme 2.

scopic measurements were of spectroscopic grade and were used as procured. Acetonitrile (HPLC grade) used for UV/Vis, cyclic voltammetry and for ${ }^{31} \mathrm{P}$ NMR spectroscopy was distilled twice over $\mathrm{P}_{2} \mathrm{O}_{5}$ and once over $\mathrm{CaH}_{2}$. The complexes, $\left[\mathrm{Et}_{4} \mathrm{~N}\right]_{4}$ $\left[\mathrm{Cu}_{4}(\mathrm{mnt})_{4}\right]$ and $\left[\mathrm{Et}_{4} \mathrm{~N}\right]\left[\mathrm{Cu}(\mathrm{mnt})\left(\mathrm{PPh}_{3}\right)\right]$ were synthesized by previous procedure. ${ }^{6}$

Cyclic voltammetry (CV) and Differential pulse polarographic (DPP) studies were made by using an Epsilon EC-20 machine. The electrolytic cell used was a conventional three compartment cell, in which a GCE working electrode, a Pt auxiliary electrode, and an $\mathrm{Ag} / \mathrm{AgCl}$ reference electrode were employed. The CV and DPP measurements were performed at room temperature using $0.2(\mathrm{M}){ }^{n} \mathrm{Bu}_{4} \mathrm{NClO}_{4}$ as the supporting electrolyte in $\mathrm{CH}_{3} \mathrm{CN}$ normally under a scan rate of $100 \mathrm{mV} \mathrm{s}^{-1}$ for $\mathrm{CV}$ and at $20 \mathrm{mV} \mathrm{s}^{-1}$ scan rate for DPP respectively. The ferrocenium/ferrocene couple was used as the internal standard $\left(E_{0}=0.53 \mathrm{~V}\right.$ under experimental condition). Electronic absorption spectra were recorded with the help of a USB2000 $\mathrm{UV} / \mathrm{Vis}$ Spectrometer and ${ }^{31} \mathrm{P}$ NMR spectra were recorded on JEOL JNM-LA 400 FT-NMR machine.

\section{Results and discussion}

Figure 1 represents the interconversion between tetramer and monomer $\mathrm{Cu}-\mathrm{mnt}$ complex under sufficient excess of the substrates like $\mathrm{PPh}_{3}$ and elemental sulfur or selenium. To understand this catalytic cycle, a representative forward part of the reaction in the conversion of tetramer to monomer on the addition of $\mathrm{PPh}_{3}$ was followed by electronic spectroscopy and also by electrochemical study. Furthermore backward or the reverse reaction like the conversion of monomer to tetramer by the addition of $\mathrm{S}$ or $\mathrm{Se}$ powder was monitored by ${ }^{31} \mathrm{P}$ NMR spectroscopy.

\subsection{Electronic absorption spectra}

The forward reaction in the conversion of tetramer to monomer in the presence of $\mathrm{PPh}_{3}$ was monitored by UV/Vis spectroscopy as shown in figure 2 . The electronic spectrum of tetramer exhibits a strong absorption band at $377 \mathrm{~nm}$ whereas monomer shows a strong absorption band at $372 \mathrm{~nm}$. The characteristic electronic spectral band at $377 \mathrm{~nm}$ of the tetramer is shifted to $372 \mathrm{~nm}$ on the addition of $\mathrm{PPh}_{3}$ in acetonitrile (figure 2). This indicates the rupture of the bridging copper-sulfur bond $\left(\mu_{2}-\mathrm{S}\right)$ involved in the formation of the tetramer. The monomer $\left\{-\mathrm{Cu}\left(\mathrm{S}_{2}-\right.\right.$ mnt) $\}$ structural unit is now stabilized by the formation of a new copper-phosphorous bond as found in $\left[\mathrm{Et}_{4} \mathrm{~N}\right]\left[\mathrm{Cu}(\mathrm{mnt})\left(\mathrm{PPh}_{3}\right)\right]$.

\subsection{Electrochemistry}

The change in the form of tetramer to monomer can also be followed by electrochemical study as shown in figure 3 . The cyclic voltammetric and differential pulse polarographic studies were performed to distinguish the electronic environment of copper center in monomer and tetramer compounds. In tetramer, each copper is coordinated by three sulfurs arising from trigonal planar geometry whereas in monomer, copper has non-equivalent environment due to the presence of two sulfur and one phosphorous donor atoms. In a typical cyclic voltammogram (CV) of the tetramer, an anodic peak potential $\left(E_{\mathrm{Pa}}\right)$ was observed at $+0.32 \mathrm{~V}$ followed by a reversible peak at $+0.41 \mathrm{~V}$ vs $\mathrm{Ag} / \mathrm{AgCl}$. Its differential pulse polarogram (DPP) exhibits the oxidation processes at $0.26 \mathrm{~V}$ and $0.36 \mathrm{~V}$, close to $E_{1 / 2}$ values of the two processes as found in its CV study. The monomer complex displayed only one irreversible peak at 
$+0 \cdot 34 \mathrm{~V}$ vs $\mathrm{Ag} / \mathrm{AgCl}$ and its DPP exhibits that oxidation process at $0.29 \mathrm{~V}$. Therefore the electrochemical responses for the tetramer and monomer differ and we used the DPP to follow a tritrimetric study using stoichiometric amount of $\mathrm{PPh}_{3}$ per copper atom present in the tetramer. After the addition of one equivalent $\mathrm{PPh}_{3}$ in the tetramer, the DPP of the resultant solution is drastically changed. The first oxidation peak of the tetramer is now almost disap-

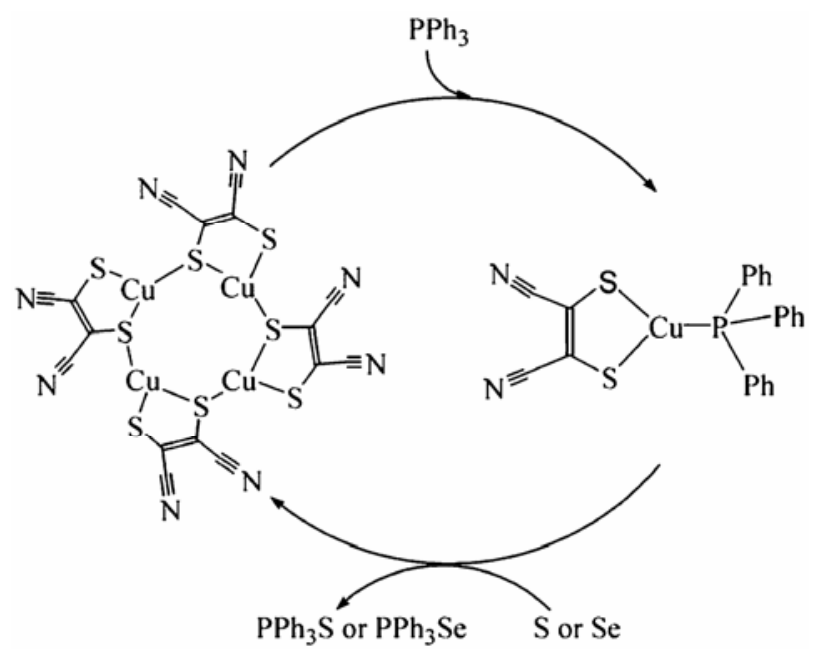

Figure 1. The catalytic cycle.

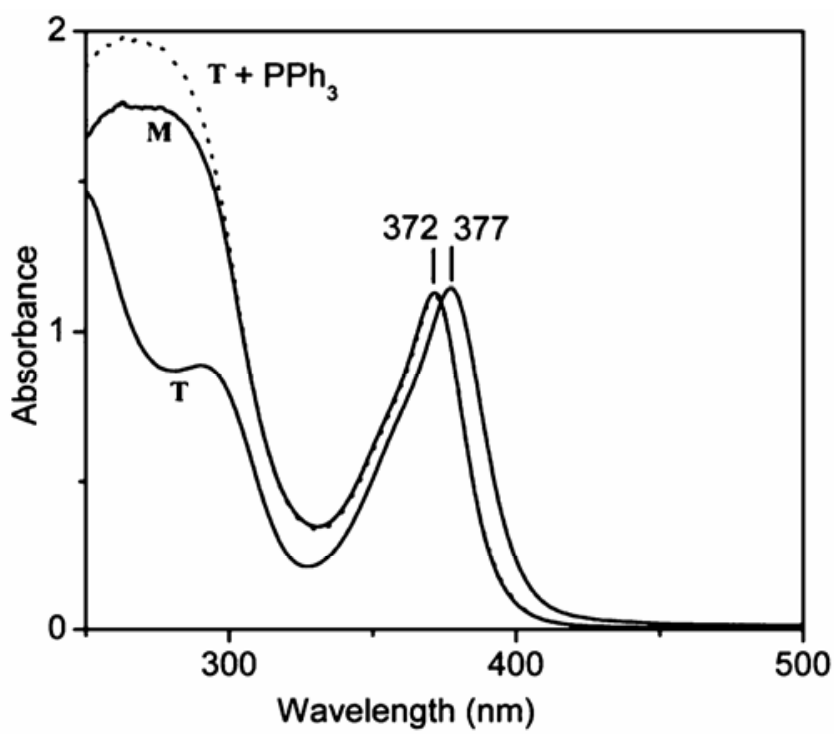

Figure 2. Conversion of $\left[\mathrm{Et}_{4} \mathrm{~N}_{4}\left[\mathrm{Cu}_{4}(\mathrm{mnt})_{4}\right]\right.$ (T) to $\left[\mathrm{Et}_{4} \mathrm{~N}\right]\left[\mathrm{Cu}(\mathrm{mnt})\left(\mathrm{PPh}_{3}\right)\right](\mathbf{M})$ as monitored by absorption spectroscopy: Solid line indicates the UV/Vis spectra of tetramer $\left(0.25 \times 10^{-4} \mathrm{M}\right)(\mathbf{T})$ and monomer $\left(1 \times 10^{-4} \mathrm{M}\right)$ (M); and broken line indicates the spectrum of the tetramer $\left(0.25 \times 10^{-4} \mathrm{M}\right)(\mathbf{T})$ with $\mathrm{PPh}_{3}\left(1 \times 10^{-4} \mathrm{M}\right)$ in $\mathrm{CH}_{3} \mathrm{CN}$ leading the shift of $377 \mathrm{~nm}$ peak of T to $372 \mathrm{~nm}$ for $\mathbf{M}$ almost overlaid with stoichiometric $\mathbf{M}$. peared with the appearance as a shoulder and the second oxidation peak shifted from $0.36 \mathrm{~V}$ toward a lower value (see figure $3 \mathrm{c}$ ) with the increase in current flow. Further addition of two, three and four equivalent of $\mathrm{PPh}_{3}$ respectively resulted the completion of the trend in drifting of the $0.36 \mathrm{~V}$ to the lower value with the final position at $0.29 \mathrm{~V}$ which is the DPP potential measured for the monomer (figure 3). The current of this peak now equals to the four equivalent of monomer which is expected to form from one equivalent of tetramer interacting with four equivalent of $\mathrm{PPh}_{3}$. These results indicate that the tetramer is ruptured by opening the bridging copper- $\mu_{2}$-sulfur bond under free $\mathrm{PPh}_{3}$ resulting the formation of new copper-phosphorous bond as present in the monomer.

\section{$3.3{ }^{31}$ P NMR study}

The backward reaction of the catalytic cycle in the conversion of monomer to tetramer by the addition of $\mathrm{S}$ or Se powder was monitored by ${ }^{31} \mathrm{P}$ NMR spectroscopy. The ${ }^{31} \mathrm{P}$ NMR experiments were carried out with the monomeric compound in $\mathrm{CH}_{3} \mathrm{CN}$ medium (figure 4). ${ }^{31} \mathrm{P}$ NMR showed resonance at

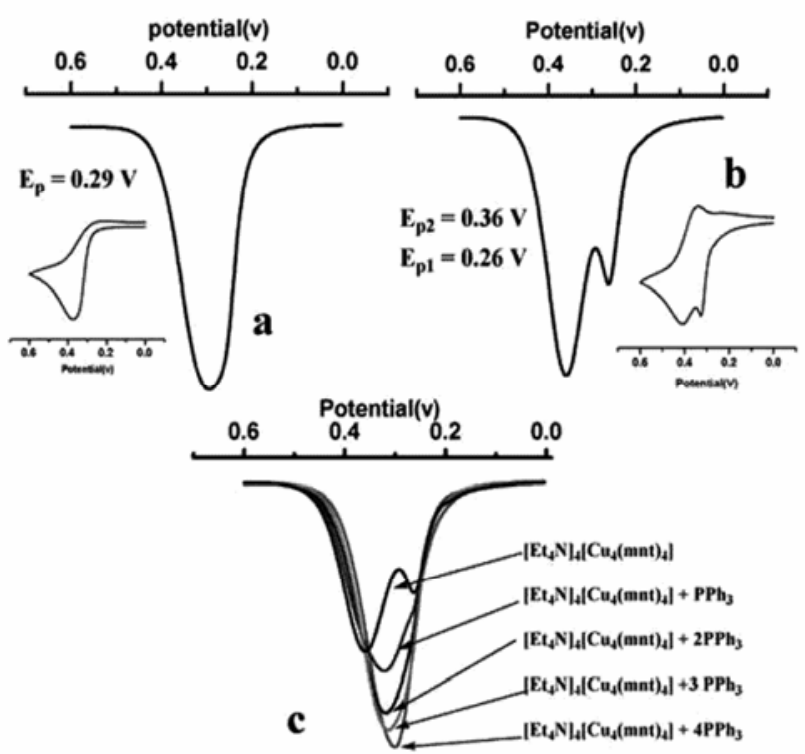

Figure 3. $\mathrm{CV}$ and DPP of monomer and tetramer were recorded at a scan rate of $100 \mathrm{mVs}^{-1}$ over the potential range of interest, 0 to $+0.60 \mathrm{~V}$ in acetonitrile solvent with $0 \cdot 2 \mathrm{M} \mathrm{Bu}_{4} \mathrm{NClO}_{4}$ as supporting electrolyte. (a) $\mathrm{CV}$ and DPP of $\left[\mathrm{Et}_{4} \mathrm{~N}\right]\left[\mathrm{Cu}(\mathrm{mnt})\left(\mathrm{PPh}_{3}\right)\right]\left(4 \times 10^{-3} \mathrm{M}\right)$; (b) $\mathrm{CV}$ and DPP of $\left[\mathrm{Et}_{4} \mathrm{~N}\right]_{4}\left[\mathrm{Cu}_{4}(\mathrm{mnt})_{4}\right]\left(1 \times 10^{-3} \mathrm{M}\right)$ and $(\mathbf{c})$ DPP scans of $\left[\mathrm{Et}_{4} \mathrm{~N}\right]_{4}\left[\mathrm{Cu}_{4}(\mathrm{mnt})_{4}\right]$ with successive addition of four equivalent $\mathrm{PPh}_{3}$. 

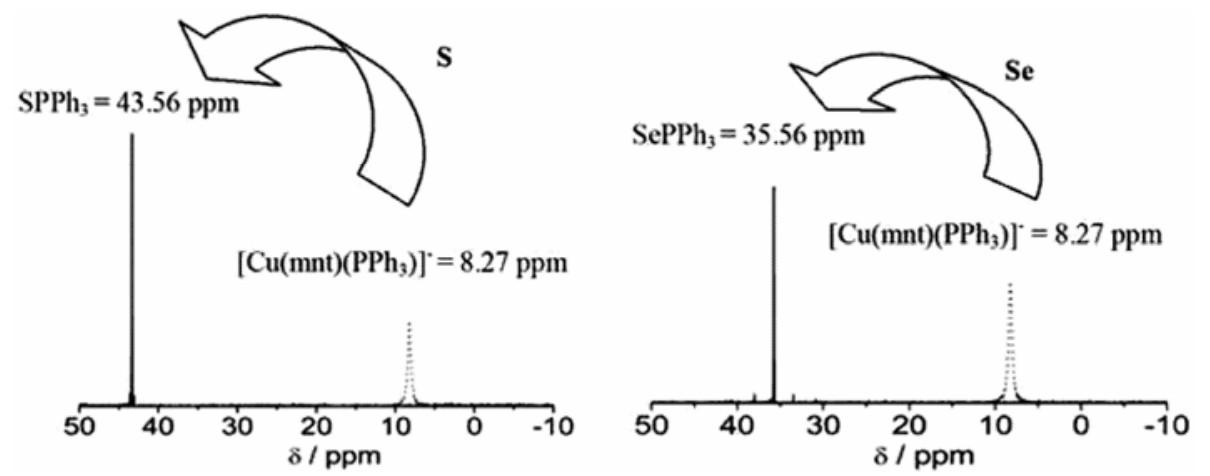

Figure 4. Left: ${ }^{31} \mathrm{P}$ NMR spectra of monomer at 8.27 (broken line) shifted to $43.56 \mathrm{ppm}$ (solid line) on addition of one equivalent $\mathrm{S}$ in $\mathrm{CH}_{3} \mathrm{CN}$; right: ${ }^{31} \mathrm{P}$ NMR spectra of monomer (broken line) at $8.27 \mathrm{ppm}$ shifted on addition of one equivalent Se to $35.56 \mathrm{ppm}$ (solid line).

$8.27 \mathrm{ppm}$ which is due to copper bound phosphorus of $\mathrm{PPh}_{3}$ ligand. This peak at $8.27 \mathrm{ppm}$ was completely replaced by the appearance of another peak at $43.56 \mathrm{ppm}$ (or $35.56 \mathrm{ppm}$ ) when stoichiometric amount of S (or Se) was added into the solution of the monomer in the NMR tube. These later peaks are assigned to the phosphorus present in $\mathrm{PPh}_{3} \mathrm{~S}$ (or $\mathrm{PPh}_{3} \mathrm{Se}$ ) ${ }^{8,9}$ This result indicates that the coordinated $\mathrm{PPh}_{3}$ in the monomer is not very stable in solution which re-organizes to form the tetramer with the formation of new bridging copper-sulfur bond once the $\mathrm{PPh}_{3}$ is removed.

The tetramer losts its cluster structure in the presence of $\mathrm{PPh}_{3}$ to afford $\mathrm{PPh}_{3}$ coordinated monomer. This species further reacts with $\mathrm{S}$ or Se and activates the reactivity of these halogens by binding with the adjoining sulfur attached with copper. In this respect, the tetramer is first cleaved by $\mathrm{PPh}_{3}$ to form the all important $\left[\mathrm{Cu}(\mathrm{mnt})\left(\mathrm{PPh}_{3}\right)\right]-$ responsible for catalysis. This catalytic oxidation reaction of $\mathrm{PPh}_{3}$ with $\mathrm{S} / \mathrm{Se}$ thus occurred rapidly under mild conditions to produce $\mathrm{PPh}_{3} \mathrm{~S} / \mathrm{PPh}_{3} \mathrm{Se}^{9}{ }^{9}$

In a typical experiment when the tetramer $(0.01 \mathrm{mmol}, 14 \mathrm{mg})$ was treated with $\mathrm{PPh}_{3}(0.1 \mathrm{mmol}$, $26 \mathrm{mg})$ in the presence of $\mathrm{S}(0.1 \mathrm{mmol}, 3 \mathrm{mg})$ or $\mathrm{Se}$ $(0.1 \mathrm{mmol}, 8 \mathrm{mg})$ in DCM at RT for $10 \mathrm{~min}$, the yield of $\mathrm{PPh}_{3} \mathrm{~S}$ was $86.20 \%$, $(25 \mathrm{mg})$. However, subtracting the amount of $\mathrm{PPh}_{3} \mathrm{~S}$ formed from the un-catalysed reaction $(11 \mathrm{mg})$ the catalytic turnover number was found to be $0.8 \times 10^{-2} \mathrm{~s}^{-1}$. Similarly for $\mathrm{PPh}_{3} \mathrm{Se}$ the total yield was $82 \%$, $(28 \mathrm{mg})$ but after the subtraction of the product formed from the uncatalysed reaction $(15 \mathrm{mg})$ the turnover number was found to be $0.6 \times 10^{-2} \mathrm{~s}^{-1}$. The recovery of tetramer after these reactions was around $86 \%$.

\section{Conclusion}

All spectroscopic and electrochemical results support a clean interconversion between tetramer and monomer complex in the presence of $\mathrm{PPh}_{3}$ with $\mathrm{S} / \mathrm{Se}$ resulting catalytic oxidation reaction of $\mathrm{PPh}_{3}$ with $\mathrm{S} / \mathrm{Se}$ under mild conditions to produce $\mathrm{PPh}_{3} \mathrm{~S} /$ $\mathrm{PPh}_{3} \mathrm{Se}$.

\section{Acknowledgments}

B K M gratefully acknowledges doctoral fellowships from the University Grants Commission (UGC), New Delhi and S S thanks the Department of Science and Technology (DST), New Delhi for funding.

\section{References}

1. (a) Stiefel E I and Matsumoto K (eds) 1996 Transition metal sulfur chemistry (Washington, DC: American Chemical Society); (b) Holm R H, Kennepohl P and Solomon E I 1996 Chem. Rev. 962239

2. (a) Messerschmidt $A$, Huber $R$, Poulos $T$ and Wieghardt K (eds) 2001 Handbook of metalloproteins volumes 1 and 2 (Chichester: John Wiley \& Sons Ltd); (b) Henkel G and Krebs B 2004 Chem. Rev. 104 801

3. (a) Maiti B K, Pal K and Sarkar S 2004 Inorg. Chem. Comun. 7 1027; (b) Maiti B K, Pal K and Sarkar S 2007 Eur. J. Inorg. Chem. 5548

4. (a) Liu C W, Staples R J and Fackler J P 1998 Coord. Chem. Rev. 174 147; (b) McCandish L E, Bissel E C, Coucouvanis D, Fackler J P and Knox K $1968 \mathrm{~J}$. Am. Chem. Soc. 90 7357; (c) Hollander F J and Coucouvanis D $1974 \mathrm{~J}$. Am. Chem. Soc. 96 5647; (d) Hollander F J and Coucouvanis D $1977 \mathrm{~J}$. Am. Chem. Soc. 99 6268; (e) Perruchas S and Boubekeur K 2004 
Dalton Trans. 2394; (f) Fackler J P and Cocouvanis D 1966 J. Am. Chem. Soc. 88 3913; (g) Perruchas S, Boubekeur K and Auban-Senzier P 2004 J. Mater. Chem. 143509

5. Dietrich H, Storck W and Manecke G 1981 Makromol. Chem. 1822371

6. Maiti B K, Pal K and Sarkar S 2008 Dalton Trans. 1003

7. Maiti B K, Pal K and Sarkar S 2008 Eur. J. Inorg. Chem. 2407
8. (a) Godfrey S M, Jackson S L, McAuliffe C A and Pritchard R G 1997 J. Chem. Soc. Dalton Trans. 4499; (b) Capps K B, Wixmerten B, Bauer A and Hoff C D 1998 Inorg. Chem. 372861

9. (a) Hesse R 1963 Ark. Kemi. 20 481; (b) Camus A and Marsich N 1989 Inorg. Chim. Acta 161 87; (c) Maraval A, Magro G, Maraval V, Vendier L, Caminade A-M and Majoral J-P $2006 J$. Organometal. Chem. 691 1333; (d) Buckland S J and Davidson R S 1987 J. Photochem. 3639 